\title{
La novela mexicana entre lo nacional y lo cosmopolita: gestación de las líneas en debate
}

\author{
MARÍA Rita PlanCARTE MARTÍNEZ
}

\section{Resumen:}

Este artículo tiene como finalidad reseñar el origen y desarrollo de la tradición literaria mexicana en el siglo diecinueve, a partir de la premisa de que en ese proceso se puede reconocer un continuo desplazamiento entre posiciones estéticas antagónicas. Se examina la forma en que tuvo lugar la gestación de líneas en debate que se traducen en dos tendencias principales: una nacionalista y otra cosmopolita, mismas que se disputan históricamente el predominio como directriz preponderante en la expresión literaria mexicana. Se distingue cómo se ha construido una tradición signada por las principales formas que asume el sentido y función de lo literario en los distintos momentos del proceso cultural decimonónico. Dicha tradición se bifurca en dos grandes ejes, uno que asume el ejercicio literario como forma de incidir en la modificación de la realidad inmediata y otro que supone la actividad estética como una práctica con finalidad en sí misma y, por ende, sin relación con el entorno social. En esta divergencia que atraviesa el proceso literario mexicano, se rastrea un permanente debate sobre la palabra, que pone de manifiesto una relación de dominación-subordinación entre dichas líneas.

\footnotetext{
${ }^{*}$ Profesora-investigadora. Universidad de Sonora.
} 
Palabras clave:

Literatura mexicana del siglo XIX, historia literaria, nacionalismo, cosmopolitismo, cultura mexicana, romanticismo, modernismo.

La novela mexicana ha transitado los más diversos y plurales caminos, la crítica ha intentado establecer un corpus con lo que, de alguna manera, se ha sistematizado y organizado el desarrollo del género en el país; así la nómina de autores y obras generalmente se divide y se subdivide de acuerdo a épocas, movimientos, tendencias o temáticas comunes. En esta sistematización de los distintos momentos por los que ha pasado la novela en México, se puede descubrir un debate implícito en cuanto a las preocupaciones estilísticas que pugnan, de manera casi permanente, por adscribirse y optar por lo "moderno" o por lo "tradicional"; por lo "extranjerizante" o por lo "nacional"; por la "imitación" o por lo "original"; por lo "estetizante" o por lo "comprometido". Incluso ha tenido larga presencia en las letras mexicanas una deseada, aunque pocas veces alcanzada, "unión de lo cosmopolita con la conciencia nacional". Estas tendencias contradictorias revelan el debate estético sobre el que se ha construido una tradición novelesca con características capaces de individualizarle como expresión estética frente a otras formas similares generadas en otras latitudes.

Las posturas antagónicas ante el hecho estético se originan en nuestra misma tradición literaria, en la medida en la que el ejercicio de la escritura como práctica cultural se ha ubicado como una forma privilegiada de expresión que, al mismo tiempo que es una actividad con características específicas, genera una significación que va más allá del texto mismo. Esto es, forma parte medular de la construcción del imaginario cultural -culto, por supuesto- en su calidad de representación estética de la experiencia vital.

La novela, y se pudiera decir que la literatura mexicana en general, se ha desplazado en esas dicotomías fundamentales, derivadas de los proyectos ideológico-estéticos que han coexistido en pugna desde el nacimiento de la nación. Para cada uno de estos proyectos, la expresión literaria tendría una función y una validez distintiva; indicadora de que aquellos estilos preferidos en determinados momentos históricos corresponden no sólo a una modalidad esté- 
tica, sino también a una manera de entender y expresar la función misma de lo literario en términos culturales.

La presencia de estas tendencias encontradas se remonta a los orígenes mismos de la expresión literaria nacional por ello, volviendo a ese pasado se tratará de recuperar la evolución de este debate en los momentos más relevantes de la historia de las letras mexicanas.

\section{En todas partes se cuecen habas}

El estertor colonial sorprendió a los escritores -todavía novohispanos- instalados en el neoclásico y agrupados en la "Arcadia Mexicana" habitando un mundo pastoril de ovejas y églogas en el que repentinamente penetraron, de la mano de Joaquín Fernández de Lizardi, las voces del pueblo que disonaban terriblemente en el idílico universo de los árcades. Con semejante irrupción de la expresión rústica en los cultos territorios literarios, inicia en México la lucha por el dominio de la palabra.

Ante tal arremetida, los poetas neoclásicos defendieron con tesón su espacio bucólico y la repelieron ferozmente utilizando todos los recursos a su alcance. Acudieron a todos sus modelos latinos o españoles o franceses- y a las poéticas en boga, para justificar con Luzán y Boileau cuáles eran los temas y las formas válidas para la expresión literaria. La égloga pastoril, con sus tragedias amorosas atenuadas por el ameno entorno forestal; la poesía satírica de cuidada factura, con sus cultas denuncias de los males de la época; la fábula al estilo entonces en boga, de inveterado tono moralista, eran las fórmulas legítimas que admitían en el ejercicio literario; a ellas y a su preceptiva se debía acudir para escribir correctamente.

No conformes con definir y establecer lo que debía ser la práctica artística verbal, los miembros de la Arcadia, encabezados por

${ }^{1} \mathrm{La}$ “Arcadia Mexicana” se formó a imitación de la romana y fue fundada a principios del diecinueve. Sus miembros, entre los que se cuentan además de Lacunza, Anastasio María de Ochoa y Bustamante, Francisco Manuel Sánchez de Tagle, Manuel Martínez de Navarrete, entre otros, seguían la preceptiva neoclásica y publicaban sus poemas en los periódicos de la época. 
Juan María Lacunza, ${ }^{2}$ atacaron a quien más tarde sería el editor de "El pensador mexicano" denostando sus escritos y acusándolo de agraviar el honor literario nacional.

Las páginas de El Diario de México (1805-1817) dieron cabida desde fines de 1811 hasta mayo de 1812, a la polémica viva que enfrentaba la preceptiva y la estética conservadora con la liberalidad y desreglamentada expresión que cultivaba Fernández de Lizardi. No voy a entrar en los detalles de la discusión, que se pueden seguir en el ensayo que al tema dedica Luis Mario Schneider en su libro Ruptura y continuidad. La literatura mexicana en polémica. Resumiré sólo lo que considero los puntos más importantes y que interesan al asunto central de este trabajo: El carácter supranacional, culto y aristocrático de la literatura defendido por los miembros de la Arcadia Mexicana contra lo nacional, coloquial y democrático propuesto por "El pensador mexicano".

Para los árcades, los escritos de Lizardi eran un atentado porque desprestigiaban la producción literaria nacional a los ojos de los extranjeros, pues si éstos hubieran tenido conocimiento de tanto desatino lizardiano, pudieran haber llegado a la terrible conclusión de que las letras mexicanas carecían de esplendor porque no seguían las pautas preceptivas marcadas desde allende los mares. De la misma manera, acusaban al disidente de ser un escritor de escaso talento y su obra un asalto contra las bellas letras, a lo cual el impugnado contestó diciendo irónicamente que "en todas partes se cuecen habas", es decir, que malos y buenos escritores había en todas partes.

La temida opinión negativa de los extranjeros sobre la producción literaria nacional tenía por lo menos dos sentidos primordiales en las letras patrias de aquel momento. Por un lado, la conciencia de que los escritores eran partícipes de una práctica que traspasaba fronteras, es decir, que su labor se entendía como un ejercicio inscrito en una gran tarea universal compartida por todos los inspirados poetas $y$, por otro, el cumplir con la obligación de estar a la

2 Luis Mario Schneider en Ruptura y continuidad. La literatura mexicana en polémica menciona a este autor como José María Lacunza; parece haber una confusión debido al nombre casi idéntico del poeta, sólo que José María pertenece a una generación posterior. 
altura de las prácticas literarias extranjeras. Para los miembros de la Arcadia Mexicana, es evidente su deber de escribir de la misma forma que en otras partes - digamos España- para ser colaboradores de esa empresa superior y obtener productos de tanta calidad literaria y tan valiosos como los foráneos.

En este punto de partida hay algo de paradoja porque, si bien se cree fervientemente que los terrenos literarios se ubican más allá de las dimensiones territoriales de los países, esto es, en un ámbito superior e incontaminado, también se presume que la práctica concreta de los individuos - poetas y escritores- lleva la marca indeleble del lugar al que pertenecen y su obra es, por lo tanto, representativa de la capacidad de su propia cultura para adaptarse a las exigencias formales y temáticas propias del ejercicio literario. Ser tan cultos como los otros, estar a la altura de los demás, participar dignamente en el concierto literario supranacional es un ideal que abriga cierta conciencia nacional, definida no por lo distintivo del país sino por la posibilidad de ser afluentes al torrente más amplio de la literatura como expresión universal. Al respecto dice Luis Mario Schneider, explicando algunos términos de la querella entre Lacunza y Lizardi:

Reiteradamente a lo largo de la discusión volverá a la misma tesis: el valor de la cultura nacional no se mide por sus valores intrínsecos, sino por su aportación a una única lírica tradicional y por la opinión extranjera que, a la manera de una comadre, enjuicia la apariencia de la vecina. La cualidad literaria debe partir para Lacunza de una probidad en el lenguaje y no de la funcionalidad en el medio que ella se genera, circula y demuestra su verosimilitud, su identificación: "Los papeles públicos o impresos de una nación son el anteojo por donde se divisan su carácter y su genio; nosotros no debemos, por más que nos inste el flujo de escritor o el interés, dar motivo a ejercitar a la crítica extranjera partidaria siempre de las glorias de su país, y rival de las del ajeno". (Schneider 57)

Lo más interesante de la afirmación anterior es que niega la posibilidad de apropiarse del discurso literario para adecuarlo a la 
realidad nacional y darle una utilidad específica como práctica cultural. Opinión que está en las antípodas de la de Lizardi, en cuya obra se puede descubrir una orientación hacia el momento histórico inmediato, pues su palabra trataba de educar y con ello mejorar las condiciones sociales, política y morales de la bisoña nación, mediante la reapropiación y refuncionalización de la expresión literaria. De ahí que, por ejemplo, en El Periquillo Sarniento (1816) recurra a la reelaboración de la imagen del pícaro, proveniente de la más rancia tradición española, caracterizándolo como mexicano y orientándolo al público no necesariamente ilustrado de la época.

Por otro lado, los detractores de Lizardi estaban seguros de que el pueblo era completamente incapaz de comprender la sensibilidad poética. Su ejercicio estaba dirigido a los cultos iniciados en los meandros de la lengua de Virgilio y encontraban verdaderamente desastroso el ingreso de voces pueblerinas en lo que debería ser expresión sublime de lo más egregio del ser humano. Dice Schneider en el citado libro que:

[Lacunza] No sólo acusa de falta de sensibilidad al pueblo para crear literatura, sino que delata su impotencia para entenderla: "Pero me parece arriesgado que la citada poesía [la de Lizardi] corra generalmente, sin que al menos le precedan las siguientes advertencias de las proposiciones que pueden ser motivo de escándalo principalmente al común del vulgo, por la mayor parte idiota". (60)

A Fernández de Lizardi poco le importaba la opinión ajena, que tanto aterraba a sus detractores. Su postura era clara, creía que se debía escribir con el lenguaje del pueblo para ser entendido por el pueblo. Suponía en la expresión literaria la utilidad práctica -de alguna manera compartida con los neoclásicos- de educar y moralizar. No despreciaba el lenguaje culto pero creía que el español mexicano debía ser vehículo para la expresión artística. Consideraba los refranes y dichos populares fuentes de sabiduría vernácula y, sobre todo, las formas privilegiadas para ser comprendido por su lector, a quien siempre tenía presente. Por ejemplo, desde las primeras líneas de la novela en El Periquillo Sarniento, queda claro que el relato de Perico es un manual de vida no sólo para los hijos del 
protagonista sino para los "hijos" de la nueva república mexicana: "Queridos hijos míos, he pensado dejaros escritos los nada raros sucesos de mi vida, para que os sepáis guardar y precaver de muchos de los peligros que amenazan y aun lastiman al hombre en el discurso de sus días" (19).

En los albores de la nación, la condena por parte de los miembros de la Arcadia Mexicana de la obra de Joaquín Fernández de Lizardi, por tener el atrevimiento de dejar entrar voces populares en sus páginas, empieza a configurar uno de problemas centrales enfrentados por los literatos mexicanos a lo largo de la historia: la disyuntiva entre el uso de formas puras, cultivadas a la europea, y la reapropiación de las mismas mediante la introducción de elementos americanos, tanto sociales como lingüísticos y su orientación al público local. Optar por una u otra forma significará incorporar en el hecho estético una posición ideológica y política determinada; así se atestigua la emergencia del discurso literario como el lugar del debate entre diversas orientaciones ideológicoestéticas en pugna por el poder interpretativo.

Como sabemos, la historia le otorgó el triunfo a José Joaquín Fernández de Lizardi, su obra y su nombre inauguran todas las historias literarias a partir del México independiente, mientras los autores neoclásicos se han desvanecido y confundido con las escuelas que imitaban. Tal renombre no se debe a que aquél haya sido mejor, sino a que coincidía ideológicamente y daba lugar a la matriz estética de una expresión literaria acorde a los cambios políticos, económicos y sociales del país en gestación.

El proyecto democratizador de la palabra, la función didáctica implícita a la producción literaria y el tratamiento de temas locales, propios de la realidad inmediata, que en aquellos primeros años de independencia en ciernes propusiera Lizardi, habrían de dar origen a ese sentido esencial que reconocen los críticos en la novela mexicana. Al mismo tiempo, la actitud neoclásica aristocrática, alejada de la realidad y en busca siempre de un diálogo con la expresión literaria creada en otros escenarios, cuya intención última es insertarse y articularse a esa forma mayor, habría de dar lugar a una segunda línea de desarrollo de la literatura mexicana que, si bien no siempre ha sido dominante, se ha mantenido siempre presente. 


\section{Mexicanizar}

El tránsito a la vida independiente y al establecimiento de la nación fue para México un largo período de vaivenes políticos e inestabilidad social. Las guerras, los abruptos cambios de gobierno, la presencia hostil de fuerzas extranjera en el territorio nacional y el talante indefinido de una sociedad que no terminaba de encontrar su nuevo rumbo, no fueron el clima más propicio para el cultivo de las letras.

Los móviles de las guerras de independencia -más tarde sublimados por la historia oficial- eran tan imprecisos que, una vez lograda la autonomía, los proyectos de nación no terminaban de idearse y mucho menos en constituirse en salidas viables para la conformación del nuevo Estado. De ahí que los intelectuales, como señala José Luis Martínez:

se apartasen de la literatura para consagrarse fundamentalmente al ensayo político, a la historia y aún a la intervención directa en el gobierno de México. [...] nuestros mejores pensadores de principios del siglo XIX nunca parecieron conceder mucha importancia a la literatura, en la que quizá veían un ejercicio demasiado frívolo e inconsistente para épocas de perpetuo sobresalto y crisis sociales. (114)

De cualquier manera, aun en circunstancias tan inadecuadas se alcanzó a producir una poesía cívica que exaltaba los valores independentistas. Los poetas, que antes rechazaban los temas nativos, se convierten en ardientes cantores de los acontecimientos memorables y de los nuevos héroes patrios. Se inicia así el paso al romanticismo nacionalista, no sólo por el paulatino abandono de las formas neoclásicas sino por el nuevo animo que guía la expresión.

Los conceptos románticos en que se funda la independencia se acomodan a todas las esferas de la actividad, desde la política hasta la vida amorosa. La subjetividad del individuo se proyecta en la unidad nacional, la libertad en su soberanía, en pocas palabras, la construcción de una nación se funda en la libertad de los ciudadanos y, por lo mismo, en la capacidad de éstos para articular y proyectar el sentido de su época. De ahí que la literatura adquiera un 
cariz pedagógico propagador de los principios románticos en que se funda la nación:

La "literatura" se concibió como el termómetro más sensible de la vida social, de su existencia histórica y, sobre todo, era el respaldo de la nacionalidad. [...] En ella el Estado depositaba de forma indirecta un conjunto de valores, determinados con anticipación, en los que ideológicamente se concretaba y realizaba la esencia de lo nacional, produciendo el efecto imaginario de una pretendida particularidad. (González Stephan 190)

Los escritores pelearon efectivamente por la definición y consolidación de un proyecto nacional, participando activamente del credo liberal o del conservador. En el imaginario romántico nacionalista, la función del escritor como forjador y defensor de una idea de nación no se circunscribía a lo libresco, suponía la acción paralela a la escritura; es decir, la capacidad para la participación activa en las luchas en defensa de los ideales del grupo político con el que se identificara. Y no sólo eso, las formas literarias a las que se recurrían podían ser indicadoras de su filiación:

Throughout nineteenth century Mexican literature Romanticism is identifiable with political liberalism while Classicism was the literary tenet of the conservatives. Writers of both sides were able to associate and work together in literary circles, and there never was a sustained debate in Mexico which might have led to the dominance of Romanticism over Classicism. The coexistence of the two attitudes is quite evident in poetry. (Brushwood 43)

3 Durante el siglo diecinueve el romanticismo en la literatura Mexicana es identificado con el liberalismo político, mientras que el clasicismo era la tendencia de los conservadores. Escritores de ambos lados podían asociarse y trabajar juntos en círculos literarios y nunca se dio un debate sostenido en México que pudiese haber llevado al predominio del romanticismo sobre el clasicismo. La coexistencia de las dos actitudes era algo evidente en la poesía]. 
La independencia política llevó a proclamar la necesaria emancipación intelectual. Escritores y poetas se obstinaron en configurar un rostro diferenciador a la cultura y a la literatura nacional. La gran disyuntiva de la época era repetir las formas literarias en boga en Europa o intentar la construcción de una expresión propia. En sentido inverso a lo que proponían los poetas neoclásicos, el alma romántica denostaría a aquellos autores cuyo ejercicio literario insistía en temas y ambientes europeos en agravio a lo nacional. Decía Guillermo Prieto que lo grande y trascendental de la Academia de Letrán ${ }^{4}$-la primera asociación literaria dedicada a conquistar la independencia literaria- había sido su tendencia decidida a "mexicanizar la literatura, emancipándola de toda otra y dándole carácter peculiar" (citado en Martínez 118).

Efectivamente, a partir de las propuestas de esta agrupación se retoman los asuntos nacionales, las voces del pueblo; se da una reapropiación del pasado indígena $\mathrm{y}$, sobre todo se recurre a la representación de las conductas, tipos y usos culturales populares mediante el costumbrismo, creando así una galería de personajes mexicanos, con usos característicos y preocupaciones vitales propias.

Más tarde, una vez restaurada la República y reinstalado el gobierno de Benito Juárez, Ignacio Manuel Altamirano expone la necesidad de un programa para construir la literatura nacional como formadora de la conciencia cívica. Su propuesta es en primer lugar de carácter colectivo y unificador. Llama a todos los escritores, fuera cual fuera su credo político, a la tarea común de construir la expresión nacional nutriendo sus páginas con la historia, con los héroes, con la realidad mexicana inmediata; sostiene con romántico ímpetu la finalidad moralista y educativa de la literatura; ratifica la necesaria independencia de las letras españolas. De esa fe resulta la necesidad de crear una literatura original, alejada de la imitación de modelos foráneos, vinculada a la realidad mexicana:

4 Pertenecieron a la Academia de Letrán -fundada en 1836- Guillermo Prieto, José María y Juan Nepomuceno Lacunza, Andrés Quintana Roo, Francisco Ortega, Fernando Calderón, Ignacio Rodríguez Galván, Ignacio Ramírez, entre otros destacados autores de la llamada primera generación romántica mexicana. 
En cuanto a la novela nacional, la novela mexicana, con su color americano propio nacerá bella, interesante, maravillosa. Mientras que nos limitemos a imitar la novela francesa cuya forma es inadaptable a nuestras costumbres y a nuestra forma de ser, no haremos sino pálidas, mezquinas imitaciones, así como no hemos producido más que cantos débiles imitando a los trovadores españoles y a los poetas ingleses y franceses. La poesía y la novela mexicanas deben ser vírgenes, vigorosas, originales, como lo son nuestro suelo, nuestras montañas, nuestra vegetación. (Altamirano 15-16)

No obstante, algunos escritores evaden la tarea nacionalista y se aíslan del mundo para dedicarse a cantar a los amores imposibles, a la soledad, al paisaje brumoso y al crepúsculo, creando la imagen del artista de sensibilidad exacerbada, cuya subjetividad es centro de su universo; estilísticamente recurren a las formas cultivadas en otras regiones, mismas que practican con esmero, y suponen que los temas no deben limitarse a lo inmediato nacional. De la misma manera, hubo otros autores que defendieron con su pluma el corto imperio de Maximiliano o siguieron cantando los misterios religiosos y abominando de las ideas juaristas anticlericales. Se continúa con la lectura e imitación de las literaturas europeas, de ahí que José María Vigil diga, para demostrar la vigencia de la discusión relativa a las formas del deber ser de la literatura mexicana:

Lo que perjudica a nuestros hombres de letras es el estudio excesivo de las literaturas extranjeras; ese cierto sentimiento de inferioridad que hemos heredado de la colonia, y el cual engendra una timidez que no se atreve a traspasar los límites de una servil imitación. El poeta que ha logrado reproducir la frase rebuscada de Herrera y Fray Luis de León, o las ampulosas antítesis de Víctor Hugo; el dramaturgo que viste a la mexicana a una griseta de París, o a un galán espadachín de los tiempos de Calderón de la Barca, creen haber pronunciado la última palabra del arte, y no reflexionan que olvidando lo que tienen cerca, nuestro suelo con sus espléndidas bellezas, nuestra sociedad con sus caracteres propios, con sus condiciones especiales, podrían crear cuadros y situaciones 
de indisputable mérito que abrirían un ancho camino a la literatura verdaderamente nacional. (Cit. en Schneider, Ruptura 118)

Es en este contexto en el que la ruta de la literatura mexicana se bifurca en dos grandes senderos, uno concurrido por quienes se apegan a la reelaboración, si no es que repetición, de los modelos estéticos foráneos y otro transitado por aquellos que se empeñan en dar voz a lo propio, a lo nacional. Tal bifurcación, sin embargo, era más que todo de carácter discursivo. En realidad, la mayoría de los autores del momento, incluidos los predicadores del nacionalismo, repetían las tendencias estéticas de otras latitudes aderezándolas únicamente con tonos de color local. Pocos fueron quienes lograron zafarse de tales usos y producir alguna obra distintiva. Podríamos pensar en Guillermo Prieto o en el mismo Altamirano, porque otros autores como Ángel del Campo, Rafael Delgado o José Tomás de Cuéllar se circunscribieron a albergar un localismo pintoresco en moldes romántico-costumbristas. Bastaría con pensar, por ejemplo, en el naturalismo de Santa (1903) de Federico Gamboa para reconocer cómo aparece esta corriente literaria de una forma mexicanizada.

La tendencia romántica, como la expresión nacional que busca representar la realidad mexicana se instaura como la forma privilegiada para construir la conciencia nacional, mientras que los aspectos formales literarios en la práctica no son tan relevantes como teóricamente lo proponen los nacionalistas. De Lizardi a Altamirano se va dibujando esa línea que otorga el legítimo valor literario a la representación de la experiencia vital mexicana, así como a la función educativa que se le atribuye socialmente.

Una vez conseguida la paz y planteado el nuevo proyecto modernizador, la literatura acorde a dicho proyecto, modificará su rostro en arreglo al nuevo ánimo utópico que ofrece la época: llegar a la modernidad, ser modernos.

\section{Modernizar}

Un país desgastado por las sangrientas guerras, por la constante lucha entre liberales y conservadores que buscaron imponer sus 
respectivos proyectos de nación, por las repetidas invasiones extranjeras; en pocas palabras, por el continuo sobresalto que se vivió en los primeros cincuenta años de independencia efectiva, no podía más que aspirar desesperadamente a la paz. Ésta llegó, por fin, de la mano de Porfirio Díaz y con ella una serie de transformaciones en todas las esferas de la práctica social.

La estabilidad permitió la consolidación de las instituciones y simultáneamente el establecimiento de un nuevo orden económico y social, sostenido por la férrea política de Díaz que no daba mucha cabida a la disensión.

México entró en una etapa de prosperidad aparente, debido a su apertura al capital extranjero que inyectara nuevos ímpetus a la industria extractiva, a la manufactura, a la banca, el transporte y el comercio. De esta manera, el país se empieza a integrar al mercado capitalista mundial como una economía exportadora de materias primas, básicamente, y consumidora de productos industrializados. Todo marcharía sobre ruedas para un país "enganchado a la formidable locomotora yankee", al menos por treinta años.

Ángel Rama, refiriéndose al contexto hispanoamericano, define este proceso vivido por la mayor parte de las economías del continente como "La expansión imperial del capitalismo: un sistema de exacción a bajo costo de materias primas del mundo, de complementación de su estructura económica" (Rama 23). Con esta forma de producción, se funda una relación de tipo neocolonial entre países metropolitanos y periféricos; culturalmente esto genera una tendencia a la universalización, pues al incorporarse al capitalismo se articula también a la cultura universal que éste presupone, de ahí que sus productores culturales puedan ser copartícipes de la famosa "crisis espiritual" 5 derivada de las profundas transformaciones económicas, sociales y políticas propias de ese momento imperialista.

5 En la Introducción a su Antología de Poesía Española e Hispanoamericana de 1934, de Onís apuntaba la idea del modernismo como resultado "de la crisis universal de las letras y del espíritu que inicia hacia 1885 la disolución del siglo XIX y que se había de manifestar en el arte, la ciencia, la religión, la política y gradualmente en los demás aspectos de la vida entera, con todos los caracteres, por lo tanto, de un hondo cambio histórico cuyo proceso continúa hasta hoy" 83). 
La impronta capitalista tiende a deshacer las formas tradicionales mediante las cuales la cultura se había manifestado, para modificarlas sustancialmente y adecuarla a los valores del nuevo mercado mundial en proceso de creación, según señala Rama:

El cotejo de valores debía producirse fatalmente; el afán de integrarse y equipararse a los niveles de cultura y holgura económica de los europeos se produjo como era previsible; la desvalorización de los productos nativos respecto de los productos extranjeros fue una de las consecuencias primeras, en varios sentidos explicable; la desvalorización de la creación artística tradicional fue otra. (Rama, La crítica 112-13)

De la misma manera, con el nuevo orden se creaba una nueva división del trabajo intelectual, en la que el escritor no tenía la relevante función social de mentor y tribuno de la época nacionalista, pues a estas alturas, los presupuestos románticos resultaban inadecuados e incluso gastados o anticuados. Así que hubo de darse una transformación radical en el intelectual para adecuarse a los requerimientos de los nuevos tiempos; las transformaciones económicas derivaron en la generación de una diferencia fundamental entre la labor del artista socialmente útil de los primeros años de la vida independiente y su nuevo papel en las postrimerías del siglo diecinueve, como lo explica Pedro Henríquez Ureña:

Nacida de la paz y la aplicación de los principios del liberalismo económico, la prosperidad tuvo un efecto bien perceptible en la vida intelectual. Comenzó una división del trabajo. Y como la literatura no era en realidad una profesión, sino una vocación, los hombres de letras se convirtieron en periodistas o en maestros, cuando no en ambas cosas. (165)

Aunque el modernismo alcanzó a configurarse como modelo de la producción poética de la época, indicadora de la autonomía de la literatura hispanoamericana de la antigua metrópoli española, no obstó para que en el interior de una cultura transformada por su inserción en el capitalismo regida por el criterio de productividad, 
el poeta perdiera su antigua dignidad y se convirtiera en un paria social:

Ser poeta pasó a convertirse en una vergüenza. La imagen que de él se construyó en el uso público fue la de un vagabundo, la del insocial, la del hombre entregado a borracheras y orgías, la del neurasténico y desequilibrado, la del droguista, la del esteta delicado e incapaz, en una palabra -y la más fea del momento- la del improductivo. (Rama, La crítica 57)

A pesar de los cambios culturales que se vivieron en la época, el modernismo se afilia al proceso puntual de autonomía literaria gestada entre la élite intelectual que propuso no sólo la emancipación política de la metrópoli española, sino también, como dice José Luis Martínez una "emancipación mental". Por ello, Rama considera al período en el que se da el modernismo como un período de modernización, cuyos límites cronológicos serían de 1870 a 1910, en el cual confluyen varios fenómenos que tendrán como corolario la fundación de lo que él llama la autonomía literaria americana. Esto supone el impulso a la creación de un campo literario con características propiamente hispanoamericanas que, como se apuntaba más arriba, habría primero servido como apoyo a la construcción de las nacionalidades emergentes y ahora apoyarían la configuración del nuevo rostro de las culturas americanas en contacto con el mundo. En este contexto y buscando dar cuenta del sentido y función que la literatura ha tenido en Hispanoamérica, el mismo Ángel Rama ${ }^{6}$ desde su marco interpretativo del modernismo señala que:

El fin que Rubén Darío se propuso fue prácticamente el mismo a que tendieron los últimos neoclásicos y primeros románticos de la época de la independencia: la autonomía literaria de la América española como parte de un proceso ge-

6 Siguiendo su misma línea de pensamiento, aunque no necesariamente coincidiendo en sus apreciaciones, los trabajos de Françoise Perus, Jean Franco y José Luis Martínez, entre otros, intentan explicar el modernismo en el marco de lo que en Rama entiende como el sistema literario hispanoamericano. 
neral de libertad continental, lo que significaba establecer un orbe cultural propio que pudiera oponerse al español materno, con una implícita aceptación de la participación de esta nueva literatura en el conglomerado mayor de la civilización europea, que tenía sus raíces en el mundo grecolatino. (Rama, Rubén Dario y el Modernismo 5)

Desde esta plataforma las literaturas nacionales vuelven a articularse a los conceptos relativos a la universalidad de la expresión literaria, por lo cual se inicia un diálogo con las formas procedentes de las culturas extranjeras, en el entendido de que el ejercicio regional de reapropiación llevaría a revelar lo específicamente americano. Pero, al mismo tiempo, hay una "democratización de las formas artísticas", lo cual supone la integración de las variables dialectales del español y el portugués de América en obras en cuya factura modernizada se sumaban asuntos de carácter propiamente americano, lo que supone un reconocimiento de la singularidad continental. De ahí Rama concluye que:

La modernización no es una estética, ni una escuela, ni siquiera una pluralidad de talentos individuales como se tendió a ver en la época, sino un movimiento intelectual, capaz de abarcar tendencias, corrientes estéticas, doctrinas y aun generaciones sucesivas que modifican los presupuestos de que arrancan. (Rama, La crítica 90)

Por otro lado, la división del trabajo arriba mencionada, llevaría a la conquista de la especialización literaria y artística, prefiguradora de la futura profesionalización del escritor, como un resultado del desarrollo social que propicia la movilidad social, pues el período se define por el crecimiento de los centros urbanos y las nuevas relaciones culturales propias de estos espacios, en los cuales se va conformando un público educado que será el receptor de las revistas y periódicos de la época. A pesar de lo que dice Rama en cuanto a que "El robustecimiento de tal autonomía sólo podía pasar por la ampliación de su base, es decir, por la participación de vastas masas en la emisión y recepción de mensajes literarios" (Rama, La crítica 73), la literatura -sobre todo la poesía- se convirtió, en realidad, en 
patrimonio de las clases ilustradas emergentes, producto de las nuevas condiciones económicas, que encontraban en ella la expresión de su capacidad para participar activamente del concierto literario internacional. Los productos de la época respondían al orden simbólico que suponía la existencia de una "alta cultura" -de carácter cosmopolita- de la cual las clases acomodadas buscaban participar para ganar el adjetivo de cultos que negara esa idea de barbarie consustancial a lo americano.

En México, el modernismo significó una ruptura con la realidad circundante como asunto central de la representación artística, pues éste se desplaza claramente a lugares idealizados -como París, por ejemplo- o a la representación de las reflexiones más íntimas del escritor. Asimismo, el mencionado contacto con autores de otras nacionalidades acentúa el interés por el lenguaje literario en sí. De tal suerte que es éste uno de los aspectos más minuciosamente trabajados, tanto en prosa como en poesía, por los escritores modernistas: la forma se convirtió en el medio en el que entraban en comunión y compartían su carácter de elegidos, de tocados por la magia de la santa poesía. Su postura tuvo como resultado una literatura que poco tenía que ver con el país, como dice José Joaquín Blanco:

Podría tener conexiones con Francia o con los más irreales rincones personales del autor, pero no alcanzaba público, ni relieve, ni tenía acceso a los principales problemas y a las posiciones sociales y políticas importantes de la nación. (Blanco 97)

El conocimiento y diálogo entablado con los modelos extranjeros -europeos y norteamericanos- estimularían la sofisticación de una producción artística que procuraba trascender las fronteras americanas y competir internacionalmente. Al mismo tiempo, la intercomunicación y la integración de los escritores americanos en el marco literario occidental fraguarían el sistema literario hispanoamericano, que se desarrollará plenamente en décadas posteriores.

Por otro lado, el arrebato modernizante tocó también a la prosa realista, heredera del costumbrismo nacionalista, pues ahora con la 
influencia del pensamiento positivo moderno y de las tendencias realistas y naturalistas europeas se propone una "investigación metódica de documentos sobre la naturaleza humana". La novela busca reflejar la realidad con la objetividad e indiferencia de un espejo y la observación directa debe completarse con la documentación. Aunque se haya tomado la realidad como base de las novelas costumbristas de principios de siglo -de Lizardi en adelante-, en las novelas realistas varía el propósito. El principal en este caso es llegar al conocimiento de las causas y soluciones de los problemas que estudia. Estos pueden ser de muy diversa índole: de carácter social, político o científico. De manera que si bien no se representa el entorno inmediato con el interés de representar el "alma nacional", sí se trata de buscar las soluciones a los problemas morales que aquejan a la sociedad, con lo que no varía grandemente la intención didáctica o de influencia en los lectores que se percibía como función básica en la novela romántica. Sólo que ahora los autores miran desde lejos, con curiosidad científica, esa realidad a representar; esta distancia resulta significativa porque transforma al escritor en una voz que denuncia las lacras sociales, de las que desde luego es ajeno. Por ello, los modelos europeos cuyos fines eran similares resultan imitables y logran un gran número de adeptos.

1910 fue un año crucial para las letras mexicanas. Ignorante del cataclismo que se avecinaba, el régimen de Porfirio Díaz promovió la elaboración de la "Antología del Centenario", encargada a Luis G. Urbina, que vería la luz en el marco de los fastuosos festejos de los primeros cien años de gobierno independiente. En la antología se revela una visión retrospectiva de la nación que "concluía ya su proceso de unificación, bajo un modelo liberal que, por lo menos en el plano de la cultura, seguía vivo en el ambiente" (Vital 24), poseedora de una expresión literaria cuya temática la legitimaba y, al mismo tiempo, con una literatura vigente cada vez más aristocratizante en donde "el escritor se tapa la nariz y se convierte en émulo, dentro del sistema literario, de las élites políticas y financieras que acaparan el poder en México" (Vital 26). Este texto demuestra la evolución de las letras en México y apunta la transformación de su función, tanto en cuanto al productor, como a su recepción, según se ha señalado. 
La disyuntiva que había presidido la construcción de la literatura nacional había sido el enfrentamiento entre lo extranjerizante y lo local. Es quizá a partir de la eclosión modernista en que tal oposición se asienta plenamente en la realidad literaria, porque en ese momento la disyuntiva se transfigura, no es ya lo nacional frente a lo foráneo, sino es la función misma de la literatura la que entra en debate.

Para los románticos decimonónicos, fueran liberales o conservadores, era muy claro que la función de las bellas letras era educar, moralizar, en una palabra, construir el ethos mexicano. De ahí que, enfrentarse al proceso de cambio implicado en la estética modernista -que poco interés tenía en el alma nacional- significó ahora sí una verdadera ruptura, con la consecuente creación de dos rutas distanciadas y en perpetua polémica. Tenemos ahora la contraposición entre un arte comprometido con el contexto circundante, la historia y la realidad del país, y otro que se ocupa de constituir el lenguaje y su diálogo con la tradición poética como el eje de sus preocupaciones. Como siempre, con más necedad que reflexión, en el enfrentamiento entre los herederos del romanticismo nacionalista y los nuevos modernistas no hubo lugar para el diálogo sino para la condena mutua. ${ }^{7}$ Sin embargo, la tendencia modernista se instala en el gusto del reducido público lector de la época y será más tarde, cuando Enrique González Martínez proponga torcerle el cuello al cisne, que renacerá el debate con renovados bríos.

Se puede observar, entonces, cómo en los tres momentos que hemos reseñado se distingue una lucha por dar vida y uso a la expresión literaria. En donde la orientación de ésta se definía a partir de las posturas ideológico-estéticas que presidían la producción artística. En el contexto de la cultura nacional, las posturas en pugna permanecen vigentes a lo largo de todo el siglo diecinueve, ya como predominantes, ya como subordinadas. Serán las condiciones políticas y sociales las que irán dando esas diversas acentuacio-

${ }^{7}$ Los detalles de las polémicas que, por lo general, tenían lugar en periódicos de la época, han sido objetos de varios estudios, entre los que destaca Ruptura y continuidad. La literatura mexicana en polémica de Luis Mario Schneider, en donde el autor repasa meticulosamente el decir de los polemistas. 
nes al hecho literario, mismas que, con sus respectivas transformaciones, se extienden y atraviesan el siglo veinte.

Se debe hacer notar que son, precisamente, la crítica y la historia literarias institucionalizadas -generadoras y promotoras del gusto- las que de acuerdo al talante ideológico-estético del momento privilegiarán una u otra línea. De la misma manera, habría que recalcar que en el proceso literario se dan una serie de rupturas, superposiciones, traslapes, saltos y retrocesos, de manera que en la exposición anterior se atendió al desarrollo cronológico de aquellas líneas que fueron predominantes, lo que, de alguna manera, afirma el carácter subordinado de las otras tendencias presentes en el mismo momento histórico.

Por otro lado, para definir el carácter dominante se ha recurrido, desde luego, a la exposición y valoración histórica que ha planteado la sistematización tradicional de la literatura mexicana, porque como antes se dijo, constituyen un primer paso para la organización de los materiales, por un lado y, por otro, porque es muy difícil escapar a la dimensión temporal con la que pensamos el pasado. Es más, sería muy difícil plantear la problemática de las tendencias presentes en la novela mexicana fuera del marco histórico, pues suponemos que no hay valores literarios intrínsecos sino que están marcados fuertemente por el momento histórico en el que se producen y se reciben los textos.

\section{Bibliografía}

Altamirano, Ignacio Manuel. La literatura nacional. Ed. José Luis Martínez. México: Porrúa, 1949.

Blanco, José Joaquín. "Medio siglo de literatura en México.” Política cultural del Estado mexicano. Ed. Moisés Ladrón de Guevara. México: Secretaría de Educación Pública, 1983. 93-147.

Brushwood, John. The Romantic Novel in Mexico. Columbia: University of Missouri Studies, 1954.

González Stephan, Beatriz. Fundaciones: canon, historia y cultura nacional. La historiografía literaria del liberalismo bispanoamericano del siglo XIX. Madrid: Iberoamericana; Frankfurt: Vervuert, 2002. 
Henríquez Ureña, Pedro. Las corrientes literarias en América hispánica. México: Fondo de Cultura Económica, 1954.

Lizardi, José Joaquín. El Periquillo Sarniento. México: Esfinge, 1993.

Martínez, José Luis. Unidad y diversidad de la literatura hispanoamericana, seguido de La emancipación literaria de Hispanoamérica. México: Joaquín Mortiz, 1972.

Onís Federico de. España en América. Madrid: Librería Villegas, 1955.

Rama, Angel. Rubén Darío y el modernismo (circunstancia socioeconómica de un arte americano). Caracas: Universidad Central de Venezuela, 1970.

—. La crítica de la cultura en América Latina. Caracas: Biblioteca Ayacucho, 1983.

Schneider, Luis Mario. Ruptura y continuidad. La literatura mexicana en polémica. México: Fondo de Cultura Económica, 1975.

Vital Díaz, Alberto. La cama de Procusto. Vanguardias y polémicas, antologías y manifiestos. México, 1910-1980. México: Universidad Nacional Autónoma de México, 1996. 
